\title{
Symposium on Life Histories of Cave Beetles:
}

\author{
AN INTRODUCTION
}

by

\section{Thomas L. POULSON*}

The purpose of this introduction is to provide an overview of the six papers that follow; any mistakes of interpretation are my own. These six papers were part of a symposium held at the 1973 annual convention of the National Speleological Society in Bloomington, Indiana. In addition to the speakers Drs. Thomas Poulson, David Culver, and John Holsinger were discussants and reviewed the submitted manuscripts (Dr. Terrence Marsh presented a paper on the carabid Darlingtonea but did not submit a manuscript). All references without a date refer to papers included in this symposium publication.

We are particularly indebted to Deleurance-Glaçon, Mitchell, and Barr for their previous work on cave beetles. Barr continues with his systematic work on carabids and trained four of the symposium speakers at different stages of their careers (Marsh, McKinney, Norton and Peck). Mitchell's laboratory and field study on the carabid Rhadine subterranea (Int. J. Speleol. 1971 a, b, c) and a fascinating study showing evolutionary loss of cyclic activity and reduction of the metabolic cost of activity among Rhadine species (Wiley and Mitchell, in lit.) are outstanding contributions. Deleurance-Glaçon's pioneering lab study of life cycles in troglophile and troglobite catopids (especially Ann. Sci. nat., Zool., $12^{\mathrm{e}}$ ser., 5 (1963)) is perhaps the classic. All of these workers have done milestone research studies which still stand as examples to be emulated.

This symposium especially adds to out knowledge of beetle life history in relation to within cave and between year differences in food supply and the relation of these factors to population density and to interactions between potentially competing species.

Peck's work on American catopids (Ptomaphagus) is the first in the UnitedStates to use lab studies of life history on a comparative basis in conjunction with biogeographic and evolutionary studies of a whole group (Bull. Museum Comp. Zool., Harvard, 145 (1973)). He suggests that the lack of reduced larval feeding, so common in the more evolved European Speonomus, may be explained by less evolutionary time available for adaptation to caves in N. America. Another possibility is that lower food supply during European glaciations resulted in more intense selection for energy conserving mechanisms. A third possibility is that the richer catopid

\footnotetext{
* Biological Sciences U. of Illinois at Chicago Circle, P.O.B. 4348, Chicago, Illinois, 60680.
} 
fauna in Europe led to competition, the consequence of this being divergence between opportunistic troglophiles and more evolved troglobites. By this argument, American catopids would have broader feeding and habitat niches and more flexible life cycles due to low competition with other beetle scavengers in the same cave (though competition with non-beetle scavengerdetritivores such as millipedes, flies, and diplurans is a possibility that should be explored). My own field experience with one of the less evolved American catopids, Ptomaphagus hirtus (for which Peck gives life history data with optimum food conditions in the lab), is that it has a flexible feeding niche and lays few eggs on food of low caloric availability such as leaves, but many eggs on energy rich food such as dung or carrion. Judging by variation in adult size, there is also considerable flexibility in larval growth.

A completely different beetle feeding strategy, that of predation on "cricket" (Gryllacridoidea: Rhaphidophoridae: Rhaphidophorini) eggs, has evolved convergently in three genera of American carabids (Norton, Kane and Poulson). Mitchell's work on feeding in Rhadine paved the way for Norton's continuing work on the coevolution of predatorprey interactions between the foraging strategies of the trechines Neaphaenops and Darlingtonea and their prey's (Hadenoecus) strategies for hiding and dispersing their eggs. Another aspect of this interaction, that of the life cycle of Neaphaenops in relation to the seasonal reproduction of Hadenoecus, is treated at length by Kane, Norton and Poulson and by Norton, Kane and Poulson. They use a variety of field data (timing of larval and pupal stages, recruitment of tenerals, fecundity, and increase in the female/male ratio as males die after mating) to show a clear seasonal cycle in Neaphaenops. This cycle is initiated in spring when Hadenoecus mate. The female cricket then lays many eggs over a one month period, in areas of loose substrate, and the female beetles find enough cricket eggs to produce and lay their own eggs.

Detailed field studies on beetles (e.g. above and Keith) have contributed to changing the old stenotopy explanation as the cause of apparent rarity of eggs and immatures of troglobites to an alternative explanation of real rarity based on cryptic behavior, wide dispersion, and infrequent reproduction and few eggs per female in the more evolved predatory species. Even epigean arthropod eggs are hard to find and in the detritivore troglobites such as the holometabolous Ptomaphagus, where larvae are commonly found, the eggs are especially difficult to find because silt particles adhere to the eggs. However, the rarity of immatures of predatory troglobites like the trechine carabids is real and cannot be explained by specialized microclimatic requirements (E. Racovitza or Jeannel) or by the need for antibiotics produced by microflora in clay (Caumartin, Ann. Speleol., 14 (1959)). Laboratory studies on catopid beetles and opilionids (Juberthie and Delay, Ann. Speleol., 28 (1973)) have shown that neither narrow microclimatic requirements nor clay substrate are required for normal life cycles. If anything, Peck's studies on Ptomaphagus loedingi larvae (in lit. and in Poulson and White, Science, 165 (1969)) suggest that local populations must adapt to avoid attack by microflora in the cave soil, not that the microflora protect them from fungal attack. Furthermore, both European and American biospeleologists who study the same habitat on a regular basis find some immatures of even the most specialized predatory troglobites such 
as spiders, opilionids and pseudoscorpions among the hemimetabolous forms and even the larvae of the holometabolous predatory trechine beetles. These predators are presumably longer lived than detritivores, based on size frequency data. In Neaphaenops we rarely find small larvae. This may be due to cannibalism which selects for wide dispersion and cryptic behavior.

Timing of reproductive cycles differs locally within a cave, between caves, and between years at one spot in a cave and so continued field study is required to show the existence of seasonality. I agree with Cabidoche (Ann. Speleol., 24 (1969)) that seasonal availability of food, which may be the effect of microclimatic cycles near entrances or flooding, is the basis for seasonal reproduction in many troglobites. In other cases, seasonal differences in food import by animals are the basis for reproductive seasonality in the troglobites and troglophiles that are part of the subcommunities associated with the kinds of food imported. My students and I are studying subcommunities based on bat guano and fecal dumps and leaf litter outfall from the nests of cave rats (Neotoma) as well as near entrance guano of rhaphidophorine crickets and deeper cave areas where the carabid Neaphaenops eats the Hadenoecus eggs and scatters beetle feces (Poulson, Bull. Nat. Speleol. Soc., 34 (1972)). These feces are the basis of a specialized detrital subcommunity of small mites, collembola, diplura and rare pseudoscorpions. In the deep cave, the amount of food input may vary tremendously between years as judged by trends in Neaphaenops population density (Norton, Kane and Poulson). A decrease in food input is an alternate explanation to Peck's observation of decreased Ptomaphagus loedingi population density which Peck suggests is due to his trapping. Neaphaenops population fluctuations are increases and not complicated by trapping disturbance. Keith (personal communication) sees a several fold decrease in density and concomitant increase in fecundity in the second year of his study of Pseudanophthalmus tenuis in a stream bank community.

In trechine carabids, it appears to me that predictable seasonal food input of one major food type is associated with obvious seasonal life cycles, 1-2 year life spans, and great between year fluctuations in population density. On the other hand, there is less marked seasonality of life cycles, 2-4 year life spans, and less population fluctuation when there are many kinds of food input and no one type predominates. This "spreads the risk" such that population fluctuations between sites and years are only moderate.

The beetles with marked seasonality, 1-2 year life spans, and great population fluctuation have one major food type that is strikingly seasonal in occurence. These include the cricket egg predator previously discussed (Neaphaenops) and a stream mud bank Pseudanophthalmus species where seasonal flooding is associated with worm reproduction and the beetles depend primarily on these worms for food and reproduction (Keith). Keith has used many indices to show that the population of $P$. tenuis turns over yearly and fluctuates greatly between years. He demonstrates a sequence of new teneral appearance, male spermathecal enlargement and then female ovary growth to pinpoint time of copulation, appearance of corpora lutea just after oviposition, and increase in asci of parasitic Laboulbenia fungus to show aging of adults with time after teneral recruitment. 
The species with less marked seasonality, 2-4 year life spans, and low population fluctuation have many food types available. A near entrance area with a seasonally rigorous microclimate exemplifies this situation for Pseudanophthalmus menetriesii (Kane and Poulson, in lit.). The beetles feed in rat nest areas, rat fecal dumps, and under cricket roosts when the entrance slope is cold and dry because the microarthropod prey are not active in the leaf litter. However, they preferentially spend time feeding on the entrance slope as it becomes cool and wet and microarthropod density in the litter increases. These areas would be temporarily good for larvae but would extend the life cycle, in time, if larvae were trapped by microclimatic change. Racovitza (for an opilionid) and Juberthie and Delay (for the trechine Aphaenops) (in Juberthie and Delay, op. cit.) suggest that selective slowing of egg development in cool microclimates compared to faster development of eggs laid later in warmer microclimates may give a more seasonal appearance of larvae than expected from temporal differences in egg laying. Of course, this could also tend to decrease seasonality along with differences in seasonal peaking of food on different areas near entrances. Whatever the case, it is clear that near entrance areas have food concentrations and it may be that the microclimatic sensitivity of troglobites shown by Juberthie (Ann. Speleol., 24 (1969)) allows them to exploit food rich areas near entrances by moving toward entrance slopes as the microclimate becomes favorable in spring. In addition, Keith has recently shown strong correlations between microclimate, flooding, and movement in Pseudanophthalmus tenuis (Ph. D. dissertation, U. Indiana, 1975).

The diversity of food and microhabitat types in near entrance caves is also true for the two caves where McKinney studied niche separation between Pseudanophthalmus menetriesii and $P$. pubescens. They have 2-4 year life spans and are clearly more seasonal, as judged by recruitment of tenerals, than is $P$. menetriesii alone (Kane and Poulson, in lit.). Seasonality of $P$. menetriesii and $P$. pubescens when together may be due to competitive displacement, which is possible in caves with heterogeneous food inputs of differing seasonal maxima in abundance and may be reinforced by the aggressive behavior of $P$. pubescens (McKinney). The seasonal recruitment and selective favoring of $P$. pubescens when he increased microarthropod prey, led McKinney to suggest that spatial differences in microhabitat associated with different food allowed coexistence. His subsequent laboratory studies of digging behavior and microhabitat selection are consistent with his interpretation.

The significance of the population studies exemplified by these symposium papers are seen in a community context and this is where current work is being directed. At the level of population interactions, Kane ( $\mathrm{Ph}$. D. dissertation, U. Notre Dame, 1974) has studied the bioenergetics of foraging in potential competitors (Neaphaenops and Pseadanophthalmus menetriesii) and Van Zant (in prep.) is studying potential interactions among four trechine species. Norton has studied the coevolution of prey-predator, Hadenoecus - trechine egg predator interactions (Ph. D. dissertation, Yale U., 1975). At the community level, Poulson and Kane (in prep.) have studied seasonal changes, on a temporal and spatial basis, for all the fauna of a small 
cave over one and a half years. This led to the idea of subcommunities, referred to above, based on different food types. Poulson is now manipulating food rigor (calories available/gram/area/time, e.g. leaves vs. dung) to test the subcommunity hypothesis and following it up with enclosure/exclosure experiments to test the effects of predators, like trechine beetles, on subcommunity structure. 